Principal Investigator: Jan Olek, Purdue University, olek@purdue.edu, 765.494.5015

Program Office: jtrp@purdue.edu, 765.494.6508,www.purdue.edu/jtrp

Sponsor: Indiana Department of Transportation, 765.463.1521

SPR-2200

\title{
High Performance Concrete (HPC) Bridge Project for SR 43
}

\section{Introduction}

Premature deterioration of concrete bridges in the United States has been identified as a major problem with respect to cost of repair and rehabilitation. Most often, chloride ion penetration and subsequent corrosion of the reinforcement is the cause. Many studies have been conducted to develop concrete mixtures that will better protect the reinforcement from corroding. However, due to the variability of concrete materials from one location to another, a universal solution cannot be developed. Unique approaches, each intended for a particular geographical location, are therefore needed to ensure full compatibility between locally available materials.

The objective of this research was to develop and test high performance concrete (HPC) mixtures, made of locally available materials, having durability characteristics that far exceed those of conventional concrete mixtures. Based on the results from the development of HPC, guidelines for a HPC bridge over Burnett Creek on SR 43, just north of I-65 near West Lafayette, Indiana, will be prepared. In addition, the effects of different curing conditions, with respect to temperature and moisture conditions, were evaluated. The use of $15.2 \mathrm{~mm}$ (0.6 in.) prestressing strand in girders made of $69 \mathrm{MPa}$ (10 ksi) concrete was also evaluated with respect to pullout resistance and transfer and development lengths.

In order to find solutions to the previously stated problems, the following scope was adopted:

1. Develop a high strength concrete mixture, with a compressive strength in excess of $69 \mathrm{MPa}$ (10 ksi), suitable for bridge applications using locally available materials and construction practices.

2. Investigate and evaluate the effects of two kinds of supplementary cementitious materials (silica fume and ground granulated blast furnace slag) with respect to factors such as chloride ion diffusivity, salt scaling resistance, freezing and thawing resistance, and shrinkage of concrete.

3. Compare the effects of different humidity conditions during curing of compressive strength and durability specimens.

4. Evaluate experimentally whether the existing AASHTO design requirements for transfer and development lengths are valid for the combination of $15.2 \mathrm{~mm}$ (0.6 in.) strand and $69 \mathrm{MPa}$ (10 ksi) concrete.

\section{Findings}

The conclusions drawn from this study are divided into two sections, one from the materials part of the study (concrete mixture development and testing discussed in Chapter 4) and the other from the structural part of the study (discussed in Chapter 5).

\section{Concrete Mixture Development and Testing}

1. In order to reduce possible effects of temperature and account for the change in uniformity of the raw materials used to produce concrete in the field, it is important to conduct trial pours within a few days before the actual pours are to be done.

2. The $\mathrm{ACl}$ equation recommended for calculating static modulus of elasticity can be used to determine the static modulus of concrete with a design strength of $69 \mathrm{MPa}$ (10.0 ksi).

3. The effectiveness of air-entraining admixtures (AEAs) to entrain and maintain a desired air content in fresh concrete should be carefully evaluated prior to their use in field applications. If changes in the air content of freshly mixed concrete are expected, the timing of specimen preparation is important as the compressive strength of the hardened concrete will vary approximately $5 \%$ with each $1 \%$ change in the air content.

4. Very good freeze-thaw resistance can be achieved for concrete mixes where up to $70 \%$ of the cement has been replaced with ground granulated blast furnace slag (GGBFS). Replacing some of the cement with silica fume, or a blend of silica fume and GGBFS, can also result in freeze-thaw durable concrete.

5. Using mineral admixtures, such as a combination silica fume and GGBFS or GGBFS alone, as a replacement for some of the cement may adversely affect the deicing scaling resistance of concrete. The scaling resistance can also be expected to decrease as the proportions of the mineral admixtures increase. Using $3 \%$ sodium chloride instead of $4 \%$ calcium chloride as a ponding solution will generally accelerate the deterioration. Reducing the period of moist curing and increasing the air curing period was found to improve scaling resistance for the field trial mixture containing both GGBFS and silica fume.

6. Based on the charge passed, in coulombs, during six hours, both silica fume and GGBFS will increase the re- 
sistance of concrete to chloride ion penetration. Using a ternary binders system of cement, silica fume, and GGBFS may provide the most favorable results in terms of chloride ion penetration resistance.

7. Shrinkage reducing admixture (SRA) can be used to effectively reduce drying shrinkage. However, before using SRA in concrete intended for freeze-thaw exposure, the compatibility of the SRA and the AEA must be conformed. In this study, the SRA greatly reduced the effectiveness of the AEA.

8. Increasing the moist curing time from 3 to 14 days for regular Indiana Department of Transportation (INDOT) Class $\mathrm{C}$ concrete, the time to failure of corrosion specimens was increased by at least $67 \%$.

9. Replacing a portion of the cement with GGBFS and/or silica fume and lowering the water/binder ratio resulted in concrete mixtures that greatly reduced chloride ion ingress when compared with the regular INDOT Class C concrete. This in turn substantially extended the time to failure of the corrosion specimens. After 30 weeks of exposure to $6 \% \mathrm{NaCl}$ solution, only one of 18 specimens made with GGBFS and/or silica fume modified mixture had failed while all six of the specimens made from the regular INDOT Class $\mathrm{C}$ concrete had failed after only 19 weeks.

10. Inadequate moist curing of $102 \mathrm{~mm}$ (4 in.) diameter concrete cylinders may significantly impair the compressive strength development of the concrete. Based on electrical tests, the ability of inadequately moist cured concrete to resist chloride ion ingress is also compromised.

\section{Structural Testing}

1. Measurements of concrete surface strains in specimens containing $15.2 \mathrm{~mm}$ (0.6 in.) strand and $69 \mathrm{MPa}$ (10 ksi) normal density concrete indicated that the transfer length was less than the code-assumed 50-strand diameter in the absence of longitudinal splitting cracks at the ends.

2. Six load tests on rectangular single-strand beams and two load tests on multiple-strand beams indicated that in the absence of web shear cracking near the ends, the AASHTO and ACl development length of

$$
L_{d}=\left(f_{p s}-\frac{2}{3} f_{s e}\right) d_{b}
$$

provided sufficient embedment to develop the full capacity of a single strand in the $69 \mathrm{MPa}(10 \mathrm{ksi})$ concrete mixes used. Rupture of the prestressing strands occurred in each of the eight load tests.

3. The instrumentation used in the multiple-strand development beams, namely vibrating wire gages, internal elec- trical resistance strain gages, and surface mounted strain gages, gave consistent readings throughout this study. All of the gages survived the casting, de-tensioning, and shipping processes.

\section{Implementation}

This study provided INDOT with a set of recommendations regarding the usage of HPC in bridge construction. These recommendations have been used to develop a set of provisional standards (see Appendix $G$ ) that have been utilized in the production of the girders and the construction of the deck on the SR 43 bridge over Burnett Creek near west Lafayette, Indiana.

The benefits of this research include:

- Assemblage of detailed data on the influence of various material components, temperature and moisture during curing on the properties of HPC.

- Reassessment of the existing practices regarding the development length and the transfer lengths for structural applications involving HPC.

- This information was utilized in the development of provisional specifications for the construction of the SR 43 bridge. Furthermore, similar provisions are currently being utilized in the construction of several bridges as a part of the reconstruction of I-465 in Indianapolis, Indiana.

- An increased level of awareness among INDOT's engineers and contractors about the important characteristics of HPC and the procedures that need to be followed in order to build a successful project utilizing this material.

\section{Recommended Citation}

Jonsson, J. A., J. Olek, J. A. Ramirez, C. F. Scholer, and R. J. Peterman. High Performance Concrete (HPC) Bridge Project for SR 43. Publication FHWA/ IN/JTRP-2012/17. Joint Transportation Research Program, Indiana Department of Transportation and Purdue University, West Lafayette, Indiana, 2012. doi: 10.5703/1288284314979.

View the full text of this technical report here: http://dx.doi.org/10.5703/1288284314979

Published reports of the Joint Transportation Research Program are available at: http://docs.lib.purdue.edu/jtrp/
PURDUE

\begin{tabular}{llllllllll}
\hline & $N$ & I & V & E & $R$ & S & I & T & $Y_{w}$
\end{tabular}

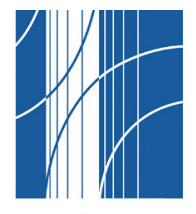

J T R P

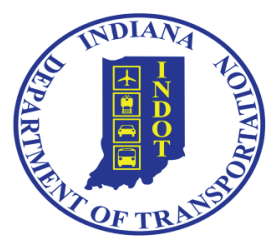

